\title{
OPEN Zinc deficiency is highly prevalent and spatially dependent over short distances in Ethiopia
}

\author{
Adamu Belay ${ }^{1,2}$, Dawd Gashu ${ }^{1 凶}$, Edward J. M. Joy ${ }^{3}$, R. Murray Lark ${ }^{4}$, \\ Christopher Chagumaira ${ }^{4}$, Blessings H. Likoswe ${ }^{5}$, Dilnesaw Zerfu², E. Louise Ander 6 , \\ Scott D. Young ${ }^{4}$, Elizabeth H. Bailey ${ }^{4}$ \& Martin R. Broadley ${ }^{4}$
}

Zinc (Zn) is an essential nutrient for human health. In Ethiopia, a high prevalence of Zn deficiency has been reported. To explore demographic variation and spatial dependencies in the $\mathrm{Zn}$ status of the Ethiopian population, we analyzed archived serum samples $(n=3373)$ from the 2015 Ethiopian National Micronutrient Survey (ENMS), a cross-sectional survey of young children, school-age children, women of reproductive age (WRA) and men conducted in all 9 regions and two city administration of Ethiopia. Serum Zn concentrations, measured using inductively coupled plasmamass spectrometry (ICPMS), were compared to thresholds based on age, sex, fasting status, and time of blood collection, after adjusting for inflammation status. Median serum Zn concentration of the population was $57.5 \mu \mathrm{g} \mathrm{dL}^{-1}$. Overall, it is estimated that $72 \%$ of the population was $\mathrm{Zn}$ deficient, with high prevalence in all demographic groups. Spatial statistical analysis showed that there was spatial dependence in Zn status of WRA at distances of up to $45 \mathrm{~km}$. Zinc deficiency is spatially dependent over short distances. Although WRA in most areas are likely to be Zn deficient, prevalence of deficiency varies at regional scale and between rural and urban inhabitants, suggesting there is scope to explore drivers of this variation, prioritize nutritional interventions, and to design more representative surveillance programs.

Zinc $(\mathrm{Zn})$ is essential for normal immune function, and physical growth ${ }^{1,2}$ and the structure and activity of more than 200 enzymes $^{3}$. Micronutrient deficiencies, including Zn, are widespread in sub-Saharan Africa (SSA), where they remain a major public health problem ${ }^{4}$. Zinc deficiency affects $17 \%$ of the world's population with the highest estimate in Africa (24\%) and Asia (19\%) based on dietary supply estimates ${ }^{5,6}$. Deficiency of Zn compromises the immune system ${ }^{7}$, resulting in increases in morbidity and mortality during early childhood and is associated with an increased risk of impaired growth and cognition ${ }^{7-10}$.

There are few data on population $\mathrm{Zn}$ status in many areas of the world, including most of SSA ${ }^{11}$. The prevalence of $\mathrm{Zn}$ deficiency at national scales in Africa has been estimated indirectly, based on national/regional food composition and food supply data, revealing that $~ 75 \%$ of the population of Eastern Africa and $81 \%$ of the Ethiopian population could be at risk of $\mathrm{Zn}$ deficiency due to inadequate dietary $\mathrm{Zn}$ supply ${ }^{11}$.

A more direct measure of population $\mathrm{Zn}$ status is based on blood plasma or serum $\mathrm{Zn}$ concentration relative to thresholds specific to age, sex and time of day. Micronutrient surveillance studies collect a range of micronutrient data from a proportion of the population, in order to make estimates of nutritional status across the represented demographic groups, and are widely used by national public health institutions to track changes in population status, including those which may be due to programmatic interventions, such as targeted supplementation or food fortification. In Ethiopia, the estimated pooled prevalence of $\mathrm{Zn}$ deficiency among pregnant women, from a systematic review of seven studies, was $59.9 \%$ (95\%CI: $51.6,67.7 \%)^{12}$ and the estimated pooled prevalence of Zn deficiency among children from six studies in Ethiopia was 38\% (95\%CI: 22.9, 55.7\%) ${ }^{12}$. This high prevalence

\footnotetext{
${ }^{1}$ Center for Food Science and Nutrition, Addis Ababa University, P.O.Box 1176, Addis Ababa, Ethiopia. ${ }^{2}$ Food Science and Nutrition Research Directorate, Ethiopian Public Health Institute, Gulele Sub City, P.O. Box 1242, Addis Ababa, Ethiopia. ${ }^{3}$ Faculty of Epidemiology and Population Health, London School of Hygiene and Tropical Medicine, Keppel Street, London WC1E 7HT, UK. ${ }^{4}$ School of Biosciences, University of Nottingham, Sutton Bonington Campus, Loughborough, Leicestershire LE12 5RD, UK. ${ }^{5}$ Department of Public Health, School of Public Health and Family Medicine, College of Medicine, University of Malawi, Chichiri, Private Bag 360, Blantyre 3, Malawi. ${ }^{6}$ Inorganic Geochemistry, Centre for Environmental Geochemistry, British Geological Survey, Nottingham NG12 5GG, UK.『email: dawd.gashu@aau.edu.et
} 
of $\mathrm{Zn}$ deficiency is consistent with reports of low dietary $\mathrm{Zn}$ intake. For example, Girmay et al. reported that the mean dietary $\mathrm{Zn}$ intake among children 6-35 months $(\mathrm{n}=6,752)$ was $1.74 \mathrm{mg} \mathrm{day}^{-1}$ at national level ${ }^{13}$, which is small compared to an Estimated Average Requirement (EAR) of $2.5 \mathrm{mg} \mathrm{day}^{-1}$. Furthermore, the phytate contents of Ethiopian diets are high which is likely to inhibit $\mathrm{Zn}$ absorption ${ }^{5}$.

Deficiency of micronutrients for different demographic groups have been reported in the most recent Ethiopian National Micronutrient Survey (ENMS), including for $\mathrm{Zn}^{14}$, and also in Belay et al. for selenium (Se) $)^{15}$. This survey is a cross-sectional study, which represents all 9 regions and two city administration of Ethiopia. The data reported in those studies were not adjusted for inflammation status, yet it is known that the presence of inflammation or infection affects the assessment of $\mathrm{Zn}$ status due to a metabolic redistribution of $\mathrm{Zn}$ from the plasma to the liver ${ }^{6,15-17}$. Inflammation biomarkers, including C-reactive protein (CRP) and $\alpha$-1-glycoprotein (AGP), are recommended to consider when estimating $\mathrm{Zn}$ deficiency ${ }^{10}$, because they provide a measure of the severity and duration of inflammation, respectively ${ }^{18}$. In the most recent National Micronutrient Survey in Malawi, estimates of the prevalence of $\mathrm{Zn}$ deficiency decreased from 62 to $52 \%$ when data were adjusted for inflammation status ${ }^{19}$. In a survey of thirteen countries, not including Ethiopia, the estimated prevalence of Zn deficiency decreased by a median of 11 (range: 4-18) percentage points, compared with unadjusted prevalences ${ }^{20}$. In addition to inflammation, the ENMS has not yet explored spatial dependencies, beyond regional or district aggregations, as seen for Se status at distances of up to $200 \mathrm{~km}$ for WRA ${ }^{15}$.

The aim of the current study was to explore $\mathrm{Zn}$ status among different demographic groups of the Ethiopian population, and to use spatial statistical models to determine spatial dependencies in Zn status for WRA. Serum Zn concentrations were measured in archived samples from the ENMS using ICPMS, which is a more sensitive analytical method than those reported previously. Inflammation markers, measured in the original ENMS programme, were used for adjustment based on established methods ${ }^{19,21}$. Geostatistical methods, used previously for $\mathrm{Se}^{15}$ and which include explicit assumptions, were applied to model the spatial variation of serum $\mathrm{Zn}$ concentration and predict the unsampled area across the country, using data for WRA, the demographic group with the largest sample size in the ENMS. These results provide novel and comprehensive information on the prevalence and sub-national variation of population $\mathrm{Zn}$ status in Ethiopia. The data contribute to our understanding of the public health significance of $\mathrm{Zn}$ deficiency, can inform the prioritization of potential interventions to alleviate $\mathrm{Zn}$ deficiency.

\section{Results}

Characteristics of the ENMS study participants. The largest number of participants in the ENMS was drawn from Oromia Region (16.9\%) and the smallest number from Addis Ababa (4.8\%) Administrative city (Table 1). Among 3,064 observations with complete information, 16.9\% were Young Children (YC), 31.4\% were School-Aged children (SAC), 13.1\% were men and 38.6\% were WRA. About a quarter of the participants were from urban areas. Around half of the SAC $(n=429 / 962)$ and YC $(n=283 / 519)$, respectively, were male. Half of the household heads were literate (Table 1).

Serum $\mathrm{Zn}$ concentrations. The estimated population mean serum $\mathrm{Zn}$ concentration is $57.7 \mu \mathrm{g} \mathrm{dL}$ (median of $57.5 \mu \mathrm{g} \mathrm{dL}^{-1}$ ) following adjustment for inflammation. Estimated population serum concentrations vary by Region. The Tigray Region had the lowest median serum $\mathrm{Zn}$ concentration $(55.2 \mu \mathrm{g} \mathrm{dL}-1)$ while the highest median serum $\mathrm{Zn}$ concentration $\left(68.3 \mu \mathrm{g} \mathrm{dL} \mathrm{d}^{-1}\right)$ was recorded for participants from Addis Ababa. The disaggregated data of average serum $\mathrm{Zn}$ concentration by administrative zones for the larger regions is indicated in Supplementary Table S1. The median serum $\mathrm{Zn}$ concentrations varied by demographic groups, with $47.1 \mu \mathrm{g}$ $\mathrm{dL}^{-1}$ observed in YC and $62.6 \mu \mathrm{g} \mathrm{dL}^{-1}$ in men (Table 2). Urban populations had a greater serum $\mathrm{Zn}$ concentration than the rural populations. Serum $\mathrm{Zn}$ concentration was greater in households whose head was educated.

Adjustments for inflammation decreased the estimated overall prevalence of $\mathrm{Zn}$ deficiency from 75.1 to $72.1 \%$ (Table 2). Those who were affected with inflammation had lower serum $\mathrm{Zn}$ status than those who were not affected. The reference values used to adjust for inflammation were $>5 \mathrm{mg} \mathrm{L}^{-1}$ for CRP and $1 \mathrm{~g} \mathrm{~L}^{-1}$ for AGP. These values are the cut-off points for determining inflammation ${ }^{21}$ and as such, some observations which are classified as not inflamed were also adjusted for inflammation.

Among the population within this study, 31\% had elevated CRP and/or AGP concentrations indicative of inflammation (Table 1). Therefore, exclusion of these groups from the analyses would reduce the sample size and may bias the results, as reported in other studies ${ }^{7}$.

We determined $\mathrm{Zn}$ deficiency prevalence across regional and demographic groups before and after correcting serum $\mathrm{Zn}$ concentration based on the BRINDA internal regression correction approach ${ }^{22}$. The prevalence of serum $\mathrm{Zn}$ deficiency was different across residence categories (55.3\% in Urban vs 74.9\% in Rural) (Table 2). The highest prevalence of serum Zn deficiency was found in Oromia (76.7\%), Tigray (75.5\%), Amhara (71.5\%) Regions, and the lowest in Addis Ababa (25.4\%).

Correlations among Serum Zn, inflammation biomarker, age and incidence of diarrhea. Serum $\mathrm{Zn}$ level was correlated with age of participant $(\mathrm{r}=0.24)$. Serum $\mathrm{Zn}$ concentration was negatively correlated with inflammation (AGP) $(\mathrm{r}=-0.14)$.

Spatial variation of $\mathbf{Z n}$ status. The spatial variation of $\mathrm{Zn}$ status was explored using the data for WRA, applying methods similar to those described in a previous study on $\mathrm{Se}^{15}$. Thus, estimates of the variogram were obtained using alternative approaches, with exponential models fitted by weighted least squares (Fig. 1).

The cross-validation errors for the model fitted to the estimates using Matheron $(1962)^{23}$ appear to be normally distributed (Fig. 2), with a median SSPE of 0.414. This model was therefore selected given that the SSPE 


\begin{tabular}{|c|c|c|}
\hline Characteristics & $\mathbf{N}$ & Percentage \\
\hline \multicolumn{3}{|l|}{ Regions } \\
\hline Addis Ababa & 148 & 4.8 \\
\hline Afar & 270 & 8.8 \\
\hline Amhara & 481 & 15.7 \\
\hline Benishangul-Gumuz & 210 & 6.9 \\
\hline Dire Dawa & 160 & 5.2 \\
\hline Gambela & 192 & 6.3 \\
\hline Harari & 168 & 5.5 \\
\hline Oromia & 517 & 16.9 \\
\hline SNNPR & 392 & 12.8 \\
\hline Somali & 193 & 6.3 \\
\hline Tigray & 333 & 10.8 \\
\hline National & 3064 & 100 \\
\hline \multicolumn{3}{|l|}{ Demographic group } \\
\hline Young children & 519 & 16.9 \\
\hline Male & 283 & \\
\hline Female & 236 & \\
\hline School age children & 962 & 31.4 \\
\hline Male & 429 & \\
\hline Female & 533 & \\
\hline Men & 402 & 13.1 \\
\hline Women of reproductive age & 1181 & 38.6 \\
\hline \multicolumn{3}{|l|}{ Residence } \\
\hline Urban & 768 & 25.1 \\
\hline Rural & 2296 & 74.9 \\
\hline \multicolumn{3}{|l|}{ Household head education } \\
\hline Educated & 1499 & 48.9 \\
\hline Illiterate & 1565 & 51.1 \\
\hline \multicolumn{3}{|l|}{ Inflammation stage } \\
\hline No inflammation & 2123 & 69.3 \\
\hline Incubation & 70 & 2.3 \\
\hline Early convalescence & 262 & 8.5 \\
\hline Late convalescences & 609 & 19.9 \\
\hline
\end{tabular}

Table 1. Characteristics of study participants in the Ethiopian National Micronutrient Survey (ENMS), 2015. Stages of inflammation were categorized as: no inflammation (CRP $\leq 5 \mathrm{mg} \mathrm{L}^{-1}$ and $\left.\mathrm{AGP} \leq 1 \mathrm{~g} \mathrm{~L}^{-1}\right)$; incubation ( $\mathrm{CRP}>5 \mathrm{mg} \mathrm{L}^{-1}$ and $\left.\mathrm{AGP}<1 \mathrm{~g} \mathrm{~L}^{-1}\right)$; early convalescence $\left(\mathrm{CRP}>5 \mathrm{mg} \mathrm{L}^{-1}\right.$ and $\left.\mathrm{AGP}>1 \mathrm{~g} \mathrm{~L}^{-1}\right)$; late convalescence $\left(\mathrm{CRP} \leq 5 \mathrm{mg} \mathrm{L}^{-1}\right.$ and $\left.\mathrm{AGP}>1 \mathrm{~g} \mathrm{~L}^{-1}\right)$ based on Thurnham et al. $(2010)^{21}$.

is close to the expected value (0.455), and it falls within the $95 \%$ confidence interval expected value when the model is valid (0.355-0.575). It had a nugget variance component-which describes the variation at finer scales than can be resolved by the sampling scheme, in addition to analytical error of 27.0. The spatially correlated variance was 39.62. The distance parameter, which controls how the spatial autocorrelation diminishes with distance, was $14.79 \mathrm{~km}$.

There is therefore limited spatial dependence in the variation of serum $\mathrm{Zn}$ concentration. A large proportion of the overall variance is attributable to the spatially uncorrelated nugget effect, and the correlated variance is spatially correlated up to distances of $45 \mathrm{~km}$, as seen in the variograms ${ }^{24}$, suggesting that $\mathrm{Zn}$ nutritional status of WRA in Ethiopia is determined by factors that vary over short distances.

The spatial variation predicted for serum $\mathrm{Zn}$ concentration for WRA across Ethiopia obtained by ordinary kriging is shown in Fig. 3a. The larger predicted serum $\mathrm{Zn}$ concentrations were found in some areas of the country including Addis Ababa while smaller predicted $\mathrm{Zn}$ concentrations were observed in Oromia Region, in line with the observations made on the population-weighted predictions aggregated by Region (Table 2). However, this approach illuminates intra-Region variation which is predicted, based upon the location of the samples. The kriging variances of the predictions of serum $\mathrm{Zn}$ concentration for WRA are shown in Fig. 3b; these are the expected squared errors of prediction which are minimized by the kriging prediction based on the variogram model.

As described previously for $\mathrm{Se}^{15}$, these interpolation errors are inevitable for all spatial predictions. This is because, given that serum $\mathrm{Zn}$ varies spatially, predictions are being made from sparse observations. However, by using the kriging variance (Fig. 3b), we can understand better where spatial predictions are reliable from a 


\begin{tabular}{|c|c|c|c|c|c|c|c|}
\hline \multirow[b]{3}{*}{ Characteristics } & \multicolumn{5}{|c|}{ Serum $\mathrm{Zn}\left(\mu \mathrm{g} \mathrm{dL}^{-1}\right)^{\mathrm{a}}$} & \multirow{2}{*}{\multicolumn{2}{|c|}{$\begin{array}{l}\text { Prevalence of serum } \mathrm{Zn} \\
\text { deficiency }(\%)^{\mathbf{b}}\end{array}$}} \\
\hline & \multicolumn{3}{|c|}{ Unadjusted } & \multicolumn{2}{|c|}{ Adjusted } & & \\
\hline & $\mathrm{N}$ & Mean $^{a}$ & Median $^{\mathrm{a}}$ & Mean $^{a}$ & Median $^{\mathrm{a}}$ & Unadjusted $^{c}$ & Adjusted $^{c}$ \\
\hline \multicolumn{8}{|l|}{ Regions } \\
\hline Addis Ababa & 148 & 67.5 & 67.9 & 68.2 & 68.3 & 27.2 & 25.4 \\
\hline Afar & 270 & 59.2 & 58.6 & 60.1 & 59.4 & 63.2 & 61.0 \\
\hline Amhara & 481 & 57.6 & 57.4 & 58.6 & 58.1 & 74.1 & 71.5 \\
\hline Benishangul-Gumuz & 210 & 57.7 & 57.6 & 58.9 & 58.5 & 69.9 & 65.7 \\
\hline Dire Dawa & 160 & 60.9 & 60.8 & 61.9 & 61.7 & 66.4 & 64.0 \\
\hline Gambela & 192 & 59.3 & 58.3 & 60.4 & 59.3 & 64.5 & 63.2 \\
\hline Harari & 168 & 56.4 & 55.7 & 57.3 & 56.9 & 71.8 & 69.7 \\
\hline Oromia & 517 & 54.8 & 54.5 & 56.1 & 55.6 & 80.0 & 76.7 \\
\hline SNNPR & 392 & 57.0 & 57.3 & 58.4 & 58.8 & 73.3 & 69.8 \\
\hline Somali & 193 & 60.5 & 59.7 & 61.8 & 60.9 & 66.5 & 63.8 \\
\hline Tigray & 333 & 54.8 & 54.0 & 55.6 & 55.2 & 78.5 & 75.5 \\
\hline National & 3,064 & 56.5 & 56.2 & 57.7 & 57.5 & 75.1 & 72.1 \\
\hline \multicolumn{8}{|l|}{ Demographic group } \\
\hline Young children & 519 & 47.2 & 46.1 & 48.6 & 47.1 & 92.1 & 89.3 \\
\hline School age children & 962 & 56.1 & 55.9 & 57.9 & 57.8 & 75.8 & 71.0 \\
\hline Men & 402 & 60.4 & 61.1 & 62.0 & 62.6 & 73.9 & 69.5 \\
\hline Women of reproductive age & 1,181 & 59.8 & 59.6 & 60.2 & 60.0 & 67.3 & 66.2 \\
\hline \multicolumn{8}{|l|}{ Residence } \\
\hline Urban & 768 & 61.8 & 61.7 & 62.8 & 62.7 & 58.1 & 55.3 \\
\hline Rural & 2,296 & 55.6 & 55.4 & 56.9 & 56.7 & 78.0 & 74.9 \\
\hline \multicolumn{8}{|l|}{ Household head education } \\
\hline Educated & 1,499 & 57.6 & 57.6 & 58.8 & 58.7 & 72.5 & 69.7 \\
\hline Illiterate & 1,565 & 55.7 & 55.5 & 56.8 & 56.6 & 77.3 & 74.1 \\
\hline \multicolumn{8}{|l|}{ Inflammation stage } \\
\hline No inflammation & 2,123 & 57.3 & 57.0 & 57.9 & 57.7 & 72.9 & 71.4 \\
\hline Incubation & 70 & 56.8 & 59.4 & 58.2 & 60.1 & 78.2 & 72.7 \\
\hline Early convalescence & 262 & 53.6 & 54.8 & 55.9 & 56.9 & 78.2 & 74.4 \\
\hline Late convalescence & 609 & 55.2 & 54.3 & 57.5 & 56.9 & 80.7 & 73.6 \\
\hline
\end{tabular}

Table 2. Serum Zn concentrations and prevalence of deficiency by study characteristics in the Ethiopian National Micronutrient Survey (ENMS). ${ }^{a}$ The estimation was weighted using the ENMS sampling weight factor. ${ }^{\mathrm{b}} \mathrm{Zn}$ deficiency was defined based on serum $\mathrm{Zn}$ considering age, sex, fasting status and time of blood

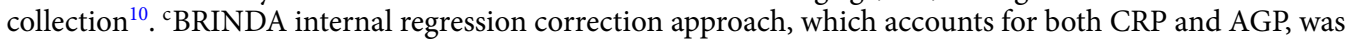
applied to calculate the prevalence of $\mathrm{Zn}$ deficiency (Namaste et al. 2017) ${ }^{22}$.

particular distribution of observations. It is apparent that there is uncertainty in most parts of the country because of the short distance over which serum $\mathrm{Zn}$ is spatially correlated and the sparse distribution of observations ${ }^{26}$. In these conditions, the predicted value tends to the mean of the observations, and the kriging variance is large. Where the kriging variance is large (shaded in light gray colors), further local sampling would be needed to determine $\mathrm{Zn}$ deficiency prevalence with greater confidence.

Figure 4 shows a probability map that the mean serum Zn concentration of WRA is below the cut-off for adequacy $\left(<70 \mu \mathrm{g} \mathrm{dL}^{-1}\right)$. The map legend includes the "calibrated phases" of the Intergovernmental Panel for Climate Change (IPCC) ${ }^{27}$, to improve the communication of uncertainty to all stakeholder ${ }^{28,29}$. This shows that WRA in large parts of Ethiopia are predicted to be 'likely' through to 'virtually certain' to have deficient serum Zn status (Fig. 4). In central parts of Ethiopia and other small parts of Northern and Eastern Ethiopia, WRA are 'unlikely' through to 'exceptionally unlikely' to be Zn deficient.

\section{Discussion}

Reanalysis of archived serum samples from the ENMS using ICMPS, with data adjusted for inflammation status, revealed $72.1 \%$ of the population of the ENMS were $\mathrm{Zn}$ deficient. The median serum $\mathrm{Zn}$ concentrations was $57.5 \mu \mathrm{g} \mathrm{dL}{ }^{-1}$, which is low compared to data from other countries ${ }^{20}$, and the lower threshold considered indicative of optimal nutritional status. The highest prevalence of $\mathrm{Zn}$ deficiency was in Oromia (76.7\%) and Tigray Regions (75.5\%); the lowest prevalence was in Addis Ababa (25.4\%). Serum Zn concentrations varied between demographic groups with median concentrations greatest among men $\left(62.6 \mu \mathrm{g} \mathrm{dL}^{-1}\right)$ and smallest among YC $\left(47.1 \mu \mathrm{g} \mathrm{dL}{ }^{-1}\right)$. Age was significantly positively associated with serum $\mathrm{Zn}$ concentration $(\mathrm{r}=0.24)$ (Table 3 ). The increase in serum $\mathrm{Zn}$ concentration with age is consistent with studies in the USA and France ${ }^{30,31}$. 


\section{a). Matheron}

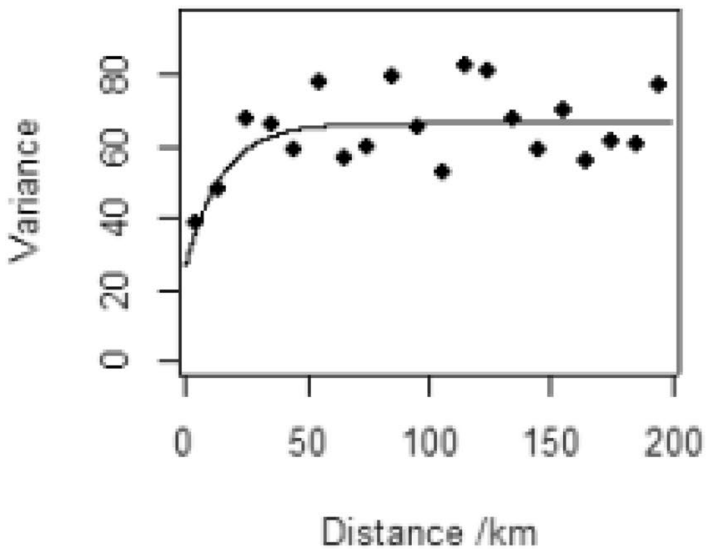

c). Dowd

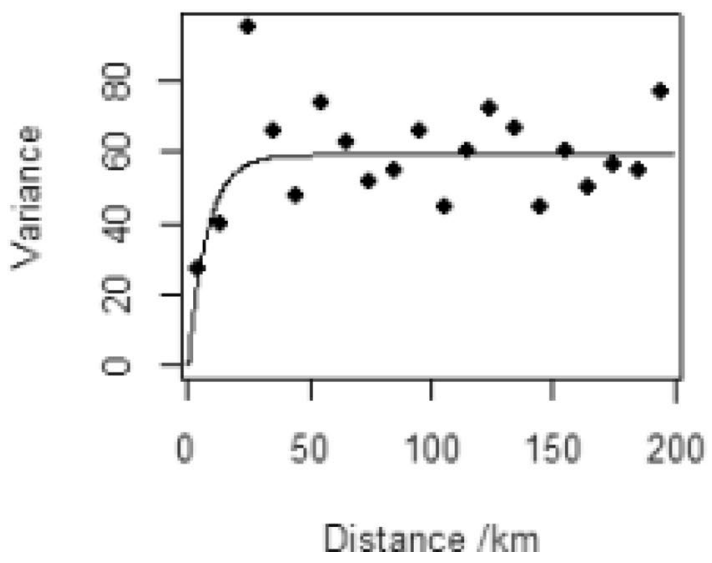

b). Cressie-Hawkins

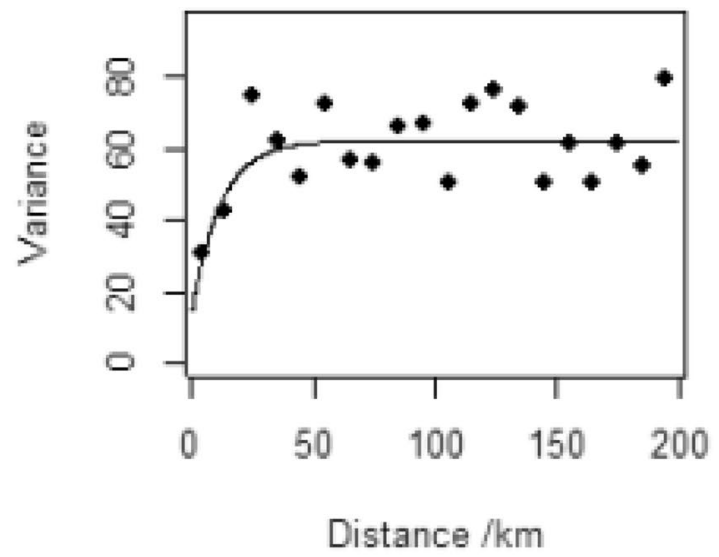

Figure 1. Variograms of WRA serum Zn estimated by different estimators; (a) Matheron estimator, (b) Cressie-Hawkins estimator and (c) Dowd estimators.

In this study, inflammation was detected among $11 \%$ and $28 \%$ of participants based on elevated serum CRP or AGP concentrations, respectively ( $9 \%$ of partcipants had elevated concentration of both). Mean serum $\mathrm{Zn}$ concentration was highest in participants with no inflammation $\left(57.3 \mu \mathrm{g} \mathrm{dL}^{-1}\right)$ and lowest in participants with inflammation in the early convalescence state $\left(53.6 \mu \mathrm{g} \mathrm{dL}^{-1}\right)$. The overall correlation between inflammation and serum $\mathrm{Zn}$ was relatively low $(\mathrm{r}=-0.14$ with AGP). The relationship between serum $\mathrm{Zn}$ concentration and inflammation biomarkers have not been widely studied ${ }^{32}$. However, it has been noted previously that infection can produce Acute Phase Reactants (APRs) and a decline of serum Zn concentration ${ }^{17}$. In a review of data from micronutrient surveys in thirteen countries, the lowest serum $\mathrm{Zn}$ concentrations were found in YC classified as being in the early convalescence state of infection, which is consistent with the finding of our current study ${ }^{20}$.

Along with inflammation, serum $\mathrm{Zn}$ concentration is also influenced by time of the day of blood collection in a fasting or nonfasting state. In this study the highest mean $\left(61.7 \mu \mathrm{g} \mathrm{dL}^{-1}\right)$ and median $\left(61.7 \mu \mathrm{g} \mathrm{dL}^{-1}\right)$ concentrations were observed in participants who had blood drawn in the fasting state, followed by samples taken in the morning from those in the non-fasting state. This is consistent with other studies ${ }^{33}$. Therefore, to determine $\mathrm{Zn}$ status in populations, inflammation biomarkers and time of the day of blood collection should be taken into consideration to estimate a reliable $\mathrm{Zn}$ deficiency prevalence.

The largest prevalence of deficiency was observed in Oromia and Tigray, followed by Amhara Regions. Tessema et al. $2018^{34}$ reported that half of the households in Tigray (50\%) and a quarter of households in Amhara (25\%) live in areas where soil concentrations of $\mathrm{Zn}$ are low, potentially limiting entry of $\mathrm{Zn}$ into local diets. In their study, the correlation between serum $\mathrm{Zn}$ and soil $\mathrm{Zn}$ was significant in Ethiopia, but it was relatively low $(\mathrm{r}=0.09)$, indicating that other determinants affect serum $\mathrm{Zn}$.

The large proportion of the population we have estimated to have inadequate $\mathrm{Zn}$ nutritional status is a finding which is consistent with other approaches that have been published. In Ethiopia, a high national prevalence of $\mathrm{Zn}$ deficiency has been estimated previously based on $\mathrm{Zn}$ supplies in the food system, which reported that $81 \%$ of the population were at risk of deficiency due to inadequate dietary $\mathrm{Zn}$ supplies, estimated from food balance sheets 


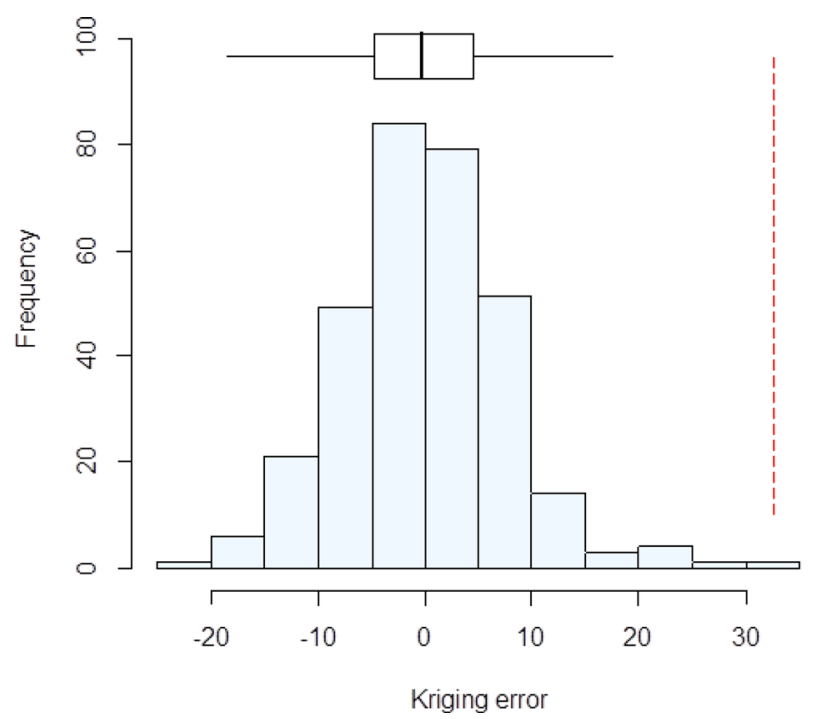

Figure 2. Histogram of the cross-validation errors using the variogram fitted to estimates obtained with the Matheron (1962) estimator ${ }^{23}$. The Box-plot shows the median and quartiles (box limits). The vertical dashed line shows the outer fence values of Tukey $(1977)^{25}$.

and regional food composition data ${ }^{11}$. A high prevalence of $\mathrm{Zn}$ deficiency ( $>20 \%$ ) has also been reported based on serum Zn status and dietary Zn intake among young children and school-aged children ${ }^{13,34-36}$ and women and pregnant women ${ }^{12,37,38}$. Several factors may contribute to a high prevalence of $\mathrm{Zn}$ deficiency in Ethiopia, where the consumption of $\mathrm{Zn}$-rich foods such as meat is $\operatorname{low}^{39}$. Food systems are highly localized in Ethiopia, particularly in rural areas, with a large proportion of dietary intakes met through subsistence production or purchases of locally-produced food ${ }^{40}$. Thus, individuals' $\mathrm{Zn}$ status may reflect the soil types and landscapes where they reside.

From the geostatistical analysis, the selected variogram (Fig. 1a, Matheron) and the fitted parameters show that about $60 \%$ of the variance is spatially dependent (i.e. the spatially dependent component as a proportion of the sum of the two variance components). However, spatial dependence is limited to about $45 \mathrm{~km}$ (i.e. $3 \times$ the distance parameter). That is to say, two observations which are close together (less than $45 \mathrm{~km}$ ) are more likely to be similar than two observations separated by a greater distance. The correlation between any two observations decays with distance, here approaching zero at about $45 \mathrm{~km}$. This is a short distance, certainly relative to the size of Ethiopia, so while we can see this short-range spatial pattern in the kriged map, the spatial pattern is seen at fine spatial scales and more detailed sampling would be needed to resolve it and to develop targeted interventions should these be desired. Figure $3 \mathrm{~b}$ also shows us the kriging variance is very high in most parts of the country. A larger proportion of the total variance is in the uncorrelated "nugget" effects and spatial dependence is seen over shorter distances. As noted above, this does have implications for the potential to design interventions that are tailored to local conditions, for example agricultural interventions that might influence $\mathrm{Zn}$ status of crops in smallholder subsistence settings, including use of inputs such as manure and fertilizer ${ }^{41}$.

These new detailed analyses of the ENMS could inform programs or policies to improve surveillance and potentially alleviate $\mathrm{Zn}$ deficiency. The joint WHO/UNICEF/IAEA/IZiNCG meeting on Zn status indicators agreed that in populations where the $\mathrm{Zn}$ deficiency prevalence rate is $>20 \%$ it should be considered a public health concern, which is the case in Ethiopia ${ }^{42}$. Potential strategies to alleviate $\mathrm{Zn}$ deficiency include the promotion of dietary diversity and biofortification, i.e. the application of $\mathrm{Zn}$ to crops via fertilizers ${ }^{43,44}$ and the release of crop varieties containing higher concentrations of $\mathrm{Zn}^{45}$. The spatial analysis of these data show that, while there is spatial dependence in the biomarker, this is limited to short distances. This limits the value of spatial mapping for designing interventions to address $\mathrm{Zn}$ deficiency at national scale. However, it does suggest that, at local scale, there could be variations in the prevalence of $\mathrm{Zn}$ deficiency which mean that more efficient interventions could be better targeted on the basis of spatial information, based either on direct sampling of the biomarker or a better understanding of the environmental factors which drive the observed variability.

Strengths of our study include the large population coverage, comprising several demographic groups, using a cross-sectional sampling design. We improved on previous estimates of population $\mathrm{Zn}$ status by using more accurate and sensitive instrumental analyses to determine $\mathrm{Zn}$ concentration in serum samples, employing advanced geostatistical methods to predict the $\mathrm{Zn}$ status of the population across unsampled locations, and by adjusted serum $\mathrm{Zn}$ concentrations considering inflammation biomarkers using different cutoffs dependent on time of blood draw. However, in the ENMS, EAs are not evenly distributed between regions proportional to size of the population. In addition, in areas of small observations such as Afar, Somali and south-east Oromia regions the uncertainty of the prediction is large which warrants further sample analysis from the areas for predictive mapping work and estimating $\mathrm{Zn}$ nutrition status of the wider population. Rural electrification and access to roads is known to improve nutritional status through increasing employment, access to health care services, improving nutritional knowledge, reducing fertility, improved access to market, and creating wealth ${ }^{46,47}$. Exclusion of EAs 

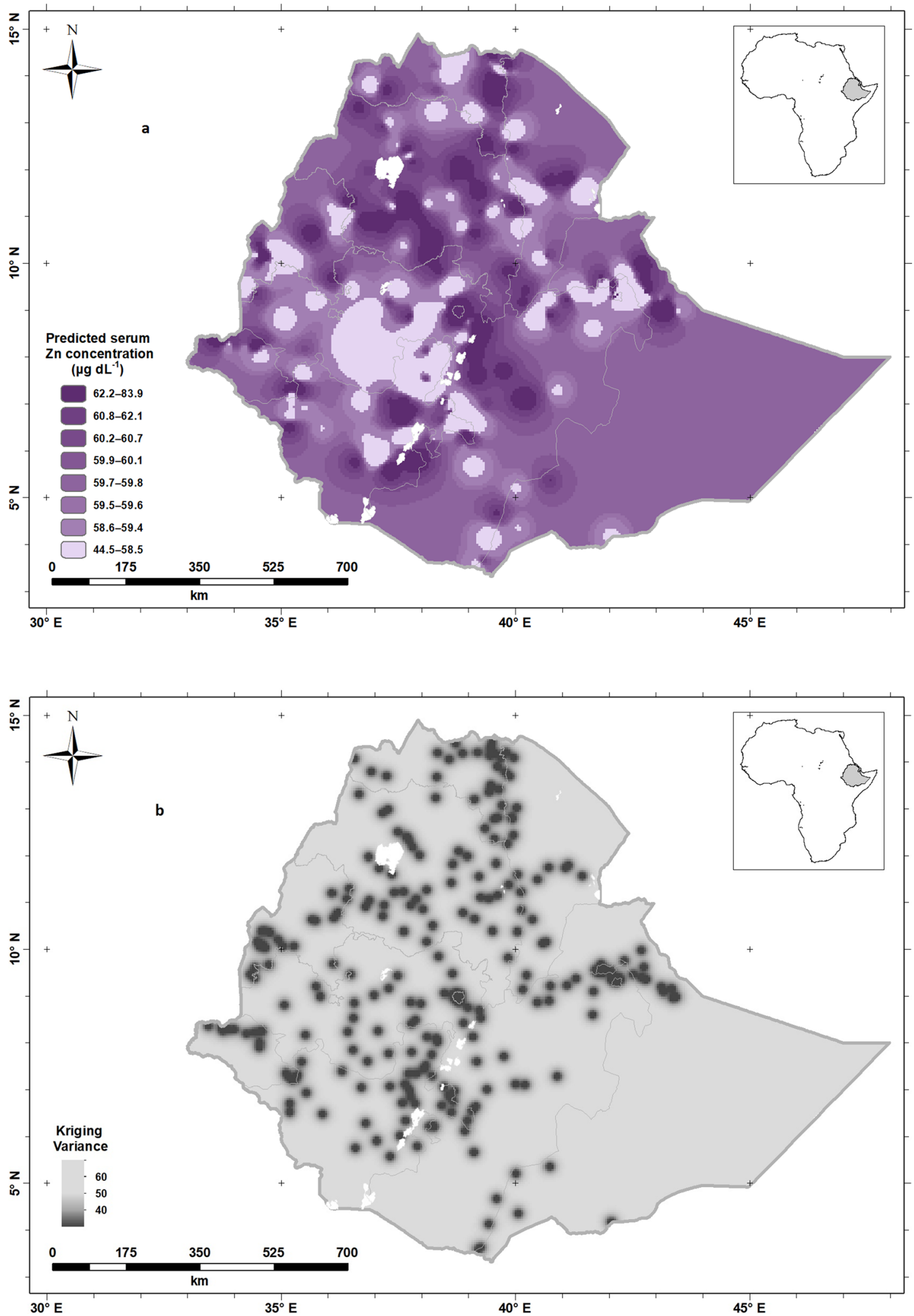

Figure 3. Predicted mean serum $\mathrm{Zn}$ concentration (a) and Predicted serum $\mathrm{Zn}$ variance (b), for women of reproductive age in Ethiopia. Created using ArcGIS 10.4.1. ESRI ArcGIS Desktop: Release 10. Environmental Systems Research Institute, Redlands. (2011).

in the present study due to lack of access to road and electricity may underestimate the magnitude of national and regional $\mathrm{Zn}$ deficiency prevalence, suggesting the importance of further studies in the areas not covered in the present study. Analyses of potential contributors to variation in serum $\mathrm{Zn}$ in different areas and among different 


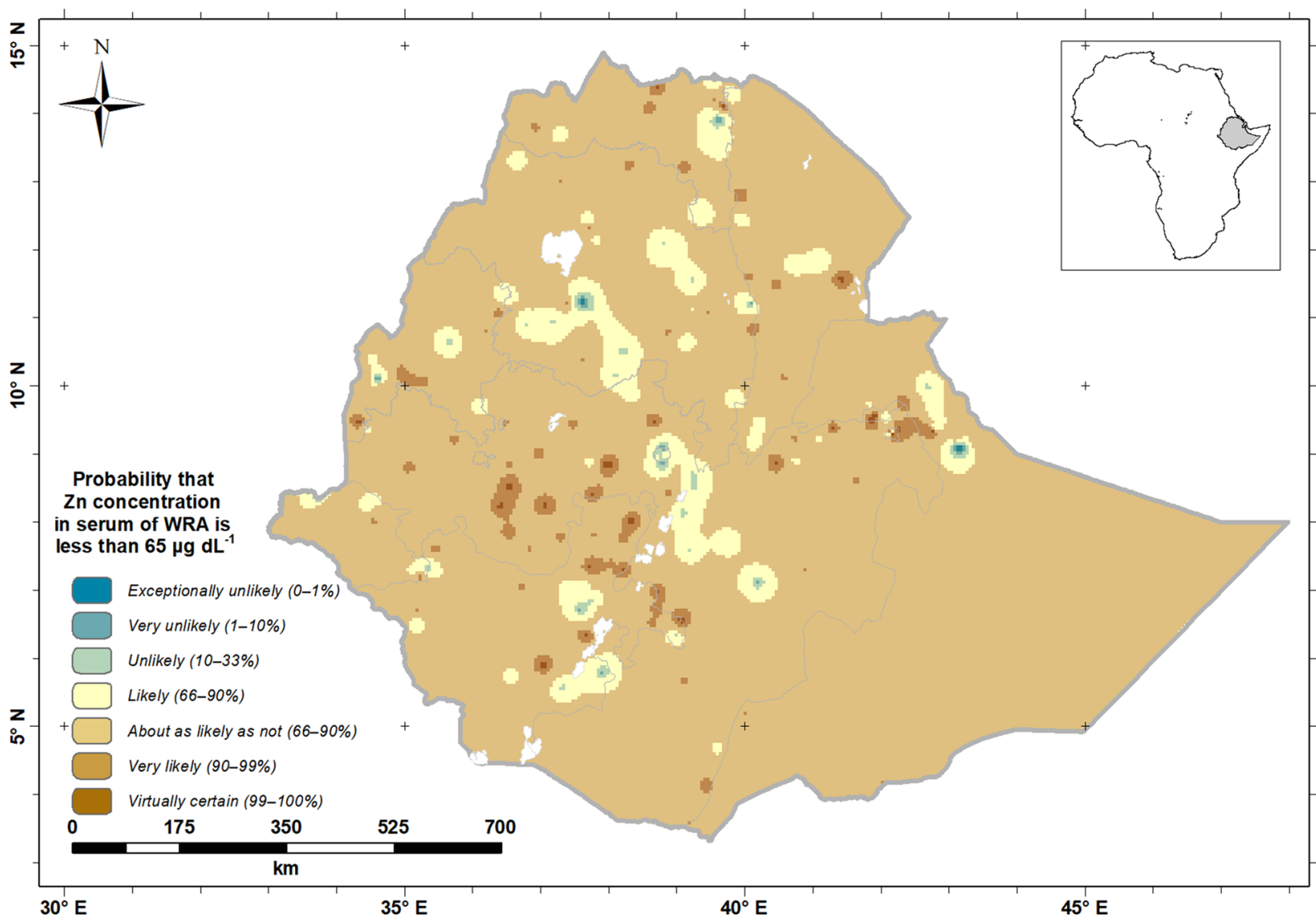

Figure 4. Probability that serum $\mathrm{Zn}$ concentration of Ethiopian women of reproductive age (WRA) would fall below a threshold $(<70 \mu \mathrm{g} \mathrm{dL}-1)$. Created using ArcGIS 10.4.1. ESRI ArcGIS Desktop: Release 10. Environmental Systems Research Institute, Redlands. (2011).

\begin{tabular}{|c|c|c|c|c|c|}
\hline & Serum $\mathrm{Zn}\left(\mu \mathrm{g} \mathrm{dL}^{-1}\right)$ & AGP $\left(\mathrm{g} \mathrm{L}^{-1}\right)$ & CRP $\left(\mathrm{mg} \mathrm{L}^{-1}\right)$ & Age (years) & Diarrhea \\
\hline Serum $\mathrm{Zn}\left(\mu \mathrm{g} \mathrm{dL}^{-1}\right)$ & 1.00 & & & & \\
\hline $\operatorname{AGP}\left(\mathrm{g} \mathrm{L}^{-1}\right)$ & -0.14 & 1.00 & & & \\
\hline $\operatorname{CRP}\left(\mathrm{mg} \mathrm{L}^{-1}\right)$ & -0.05 & 0.40 & 1.00 & & \\
\hline Age (years) & 0.24 & -0.17 & 0.08 & 1.00 & \\
\hline Diarrhea & -0.06 & 0.07 & 0.07 & -0.05 & 1.00 \\
\hline
\end{tabular}

Table 3. Spearman's rank correlations between serum Zn, inflammation biomarkers, the incidence of diarrhea, and age of all demographic groups. AGP $\alpha$-1-glycoprotein concentration, CRP C-reactive protein concentration.

demographic groups, for example data on dietary intake, and drivers of variation in food composition such as soil, crop, and livestock Zn status, as reported previously for Se in Ethiopia ${ }^{48}$ is lacking in the present study. We are not therefore able to draw conclusions about the causal effect of low serum $\mathrm{Zn}$. Different study designs will be required to identify explanatory factors contributing to the variation in $\mathrm{Zn}$ status and determine the health significance of the deficiencies observed in the current study.

\section{Conclusions}

The present study shows that $\mathrm{Zn}$ deficiency is highly prevalent in Ethiopia, and provides the first estimation which accounts for the impact of inflammation on the assessment of Zn status in Ethiopia. Risk of Zn deficiency is spatially dependent within a short distance up to $45 \mathrm{~km}$, which is likely to be due to environmental and food system factors including soil type, landscape features, and food production and distribution ${ }^{11}$. This study may inform national strategies to enhance $\mathrm{Zn}$ status of the Ethiopian population, and to improved micronutrient surveillance programs. 


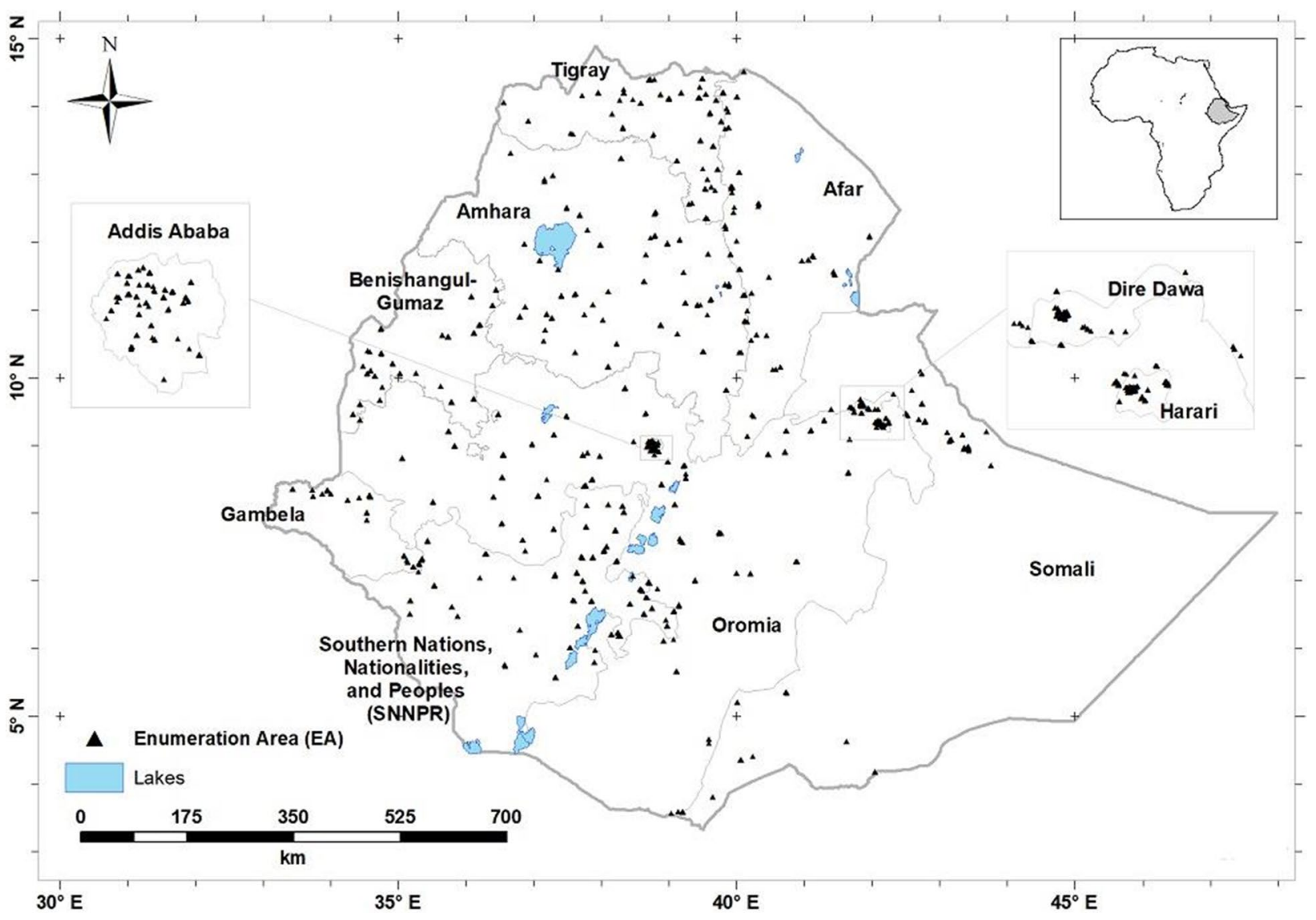

Figure 5. Locations of the centroids of $n=343$ Enumeration Areas from which study participants were recruited $^{15}$. Created using ArcGIS 10.4.1. ESRI ArcGIS Desktop: Release 10. Environmental Systems Research Institute, Redlands. (2011).

\section{Materials and methods}

Study design and sample population. The ENMS covered all nine regions of Ethiopia and two administrative cities (Addis Ababa and Dire Dawa; Fig. 5). The design of the ENMS is explained in detail elsewhere ${ }^{14,15,34}$. Briefly, the ENMS was a large, population-based cross-sectional survey of Young Children (YC, aged 6-59 months, $n=1100$ ), School Age Children (SAC, aged 5-15 years, $n=1500$ ), Women of Reproductive Age (WRA, aged 15-49 years, $n=1600$ ) and Men (aged 15-54 years, $n=500$ ) conducted between March and July 2015. The ENMS enumeration areas (EAs), or clusters, are geographic areas defined by the Central Statistics Agency (CSA) for the Ethiopia Population and Housing Census ${ }^{49}$. The survey employed stratified sampling in each of the nine regions and two administrations cities. For each region, the EAs were selected based on standard probability proportional to size (PPS). The number of EAs among regions were adjusted at the sixth root for fair allocation of EAs especially for smaller regions. A total of 366 spatially distributed EAs were selected randomly. Following the household census conducted in all selected EAs preceding the actual survey, 13 of them were excluded due to lack of infrastructure (e.g. EAs that can't be accessed by car or pack animals or are more than $5 \mathrm{~h}$ walking distance) and security issues. Within each selected EAs 11 households were randomly selected for enumeration. EAs contain on average 181 households $(150-200)^{49}$.

The present study uses two datasets: socio-demographic data collected from georeferenced households in the ENMS, and newly-generated data on Zn concentrations measured in archived serum samples from the ENMS. The data on Zn concentrations were obtained only for those individuals from the ENMS survey for whom sociodemographic data, inflammation biomarker and location information from GPS were available, and where there was at least $0.3 \mathrm{~mL}$ of archived serum sample. A total of 3373 out of $4700(71.7 \%)$ of the archived serum samples contained sufficient material for analysis of $\mathrm{Zn}$ concentration.

Data collection and analysis. Socio-demographic data. Socio-demographic information was collected using a structured questionnaire. The research assistants and supervisors were trained on data collection. The questionnaire was pilot tested in a cluster that was not selected for the actual survey. Questionnaires were refined based on the finding from the pilot testing before the actual data collection began ${ }^{15}$.

Collection, processing and analysis of serum $\mathrm{Zn}$. Blood collection and processing methods are described elsewhere ${ }^{14,15,34}$. Briefly, venous blood samples were collected from participants by trained phlebotomists and processed as per the World Health Organization (WHO) blood collection guidelines ${ }^{50}$. Samples were aliquoted 
in the field and subsequently analyzed for a range of micronutrients ${ }^{14}$. One aliquot of each sample was stored at EPHI at $-80^{\circ} \mathrm{C}$ as archived material in case analyses needed to be repeated or additional micronutrient analyses could be supported, as is the case with the present study.

The concentration of $\mathrm{Zn}$ in serum samples was determined using ICP-MS (Thermo Fisher Scientific iCAPQ, Thermo Fisher Scientific, Bremen, Germany). Samples were introduced, via a single line, from an auto-sampler incorporating an ASXpress ${ }^{\mathrm{Tm}}$ rapid uptake module (Cetac ASX-520, Teledyne Technologies Inc., Omaha, NE, USA) through a perfluoroalkoxy (PFA) Microflow PFA-ST nebulizer (Thermo Fisher Scientific, Bremen, Germany). All samples and external element calibration standards were diluted as $0.3 \mathrm{~mL}$ added to $6 \mathrm{~mL}$ of a solution containing: (1) $0.5 \% \mathrm{HNO}_{3}$ (Primar Plus grade), (2) $2.0 \%$ methanol (Fisher Scientific UK Ltd, Loughborough, $\mathrm{UK}$ ) and (3) three internal standards including ${ }^{72} \mathrm{Ge}(10 \mu \mathrm{g} \mathrm{L}-1),{ }^{103} \mathrm{Rh}(5 \mu \mathrm{g} \mathrm{L}-1),{ }^{193} \operatorname{Ir}\left(5 \mu \mathrm{g} \mathrm{L}{ }^{-1}\right)$ (SPEX Certiprep Inc., Metuchen, NJ, USA). Zn calibration standards were prepared at $0,20,40,100 \mu \mathrm{g} \mathrm{L}^{-1}$ (Claritas-PPT grade CLMS-2; SPEX Certiprep Inc., Metuchen, NJ, USA). The ICP-MS was operated in 'collision-reaction cell mode'.

The limit of detection (LOD) for $\mathrm{Zn}$ was measured as $3 \times$ standard deviation of 10 operational blanks; the limit of quantification (LOQ) was calculated as $10 \times$ standard deviation. The LOD and LOQ were 1.43 and $4.77 \mu \mathrm{g}$ $\mathrm{L}^{-1}$, respectively. Accuracy was verified by the use of two Seronorm ${ }^{\mathrm{Tx}}$ reference materials: L-1 (Lot 1801802) and L-2 (Lot 1801803) (Nycomed Pharma AS, Billingstad, Norway). These were prepared in an identical way to the samples and typically run at the start and the end of each analytical run. Average $\mathrm{Zn}$ recovery $(\% ; \mathrm{n}=24)$ when compared to accredited values determined across 10 analytical batches of blood serum was $88 \%$ and $86 \%$ for L-1 and L-2, respectively.

Data analysis. Of the total of 3373 analyzed serum samples for $\mathrm{Zn}$ concentration, 309 observations were excluded due to missing GPS coordinates $(n=101$; $m e n=5, Y C=63, S A C=24$ and WRA $=9)$, missing data on meal intake time $(n=172 ;$ men $=8 . S A C=38$ and WRA $=126)$, missing inflammation biomarker $(C R P$ and/or AGP) data $(n=30 ;$ WRA $=19$, Men $=4$ and $S A C=7)$ or a lack of socio-demographic data $(n=4 ; 2$ from SAC and 2 from WRA) with two analytical outlier datum from WRA. Thus, 3064 observations were included for descriptive statistical analyses and considered for determination of prevalence of $\mathrm{Zn}$ deficiency. The mean, median and prevalence of $\mathrm{Zn}$ deficiency were determined before and after adjustment for inflammation.

Serum $\mathrm{Zn}$ concentrations were corrected for infection using the BRINDA internal regression approach ${ }^{22}$. This was done by running a linear regression model with lnZinc as the dependent variable; and $\operatorname{lnCRP}$ and $\ln A G P$ as the independent variables. This generated the slope (regression coefficient) of $\operatorname{lnCRP}(\beta 1)$ and $\ln A G P(\beta 2)$. These two parameters were then used to adjust for the effect of inflammation, for observations whose CRP and AGP values were above the reference values. A reference value for serum $\operatorname{lnCRP}$ and $\ln$ AGP is used to avoid over-adjusting the micronutrient biomarkers among individuals with low levels of inflammation. The reference values for this analysis were the maximum value of the lowest decile for $\ln C R P(p 10)$ and that of $\ln A G P(p 10)$.

The equation was thus, adjusted $\mathrm{Zn}$ concentration $=\exp$ [unadjusted lnZinc- $\beta 1$ (CRPobserved - maximum of lowest decile for CRP) - $\beta 2$ (AGPobserved - maximum of lowest decile for AGP)]. The model was checked to ensure all assumptions were met by examining the plot of residuals, homogeneity of variance, and normality.

Descriptive statistical analyses were conducted in STATA (Version 14.0, StataCorp LLP, Texas, USA). Prevalence of $\mathrm{Zn}$ deficiency among all demographic groups in Ethiopia were determined as suggested by Hotz et al. $2003^{33}$. Zn deficiency defined as serum Zn concentration $<65 \mu \mathrm{g} \mathrm{dL}{ }^{-1}$ for morning, non-fasting samples for YC and SAC under 10 years of age and $<57 \mu \mathrm{g} \mathrm{dL}^{-1}$ for afternoon, non-fasting samples. For those 10 years old and older, a cutoff of $<70 \mu \mathrm{g} \mathrm{dL} \mathrm{L}^{-1}$ was used for males and $<66 \mu \mathrm{g} \mathrm{dL}{ }^{-1}$ was used for females for morning, non-fasting samples; the cutoff of $<61 \mu \mathrm{g} \mathrm{dL}^{-1}$ was used for males and $<59 \mu \mathrm{g} \mathrm{dL}^{-1}$ was used for females for afternoon, nonfasting samples. A cutoff of $<74 \mu \mathrm{g} \mathrm{dL}-1$ was used for men and $<70 \mu \mathrm{g} \mathrm{dL}-1$ was used for WRA for morning, fasting samples ${ }^{10}$.

Serum $\mathrm{Zn}$ concentrations were mapped at national level for WRA only. This is because WRA had the largest sample size in the ENMS and the sample covered more EAs than participants of other demographic groups in the survey. Inclusion of all age categories in the modelling could have clustering effect causing a non-reliable predictive mapping, and would have limited our scope to compare to appropriate biomarker thresholds which are specific to demographic groups due to the variation in concentration expected with age. Even though serum zinc concentration of the present study participants differs by age category, it isn't expected that the pattern of serum zinc concentration distribution to be different among these groups. This is because the study participants were either from the same households or villages dependent on local food sources. For example, our previous studies show that the spatial pattern of distribution of serum Se concentration among women of reproductive age and young children in the Amhara region was not different ${ }^{15,51}$. Ordinary kriging predictions were computed on the nodes of a $60-\mathrm{m}$ square grid. In geostatistical terminology, a prediction is obtained from the prediction distribution of a random variable at an unsampled location. This is a conditional distribution, conditional on the geostatistical model (the variogram in the case of ordinary kriging) and the observed values at sample locations. In ordinary kriging, the prediction is the mean of the prediction distribution, and its variance is the ordinary kriging variance.

Data values were first aggregated to mean values for each EA, and mean coordinates were computed for each EA. One single value was a probable outlier according to the criteria of Tukey $(1977)^{25}$. This was removed from the data for variogram estimation but was returned for spatial prediction by kriging. This is because estimates of the variogram are particularly susceptible to extreme values ${ }^{26}$ but if, as here, there is no reason to think the observation erroneous then it should be considered for local prediction.

Because of the large extent of the sampled region, all spatial analyses were done using the latitude and longitude recorded for the observations, rather than on a rectilinear grid since no single projection would be suitable at all locations. Under the usual assumptions of stationarity in geostatistics, spatial dependence is modelled in 
terms of the vector that separates locations, or lag. In this setting, the lag distance between any two points was computed as the great circle distance on a spherical approximation. This was computed using the dist Vincenty Sphere function from the geosphere package for the $\mathrm{R}$ platform ${ }^{52}$. The function final Bearing from the same package was used to obtain bearings. Note that, when distances between locations are measured on the sphere, then not all variogram functions that are suitable for use on the plane can be applied. On the sphere the exponential model is authorized ${ }^{53}$, and so it was used for all variogram modelling in this study.

Exploratory variogram analysis indicated that there was no marked directional dependence of the variogram (Supplementary Figure S1), so an isotropic variogram (Supplementary Figure S2) was estimated using the standard estimator due to Matheron $(1962)^{23}$. In addition, variogram values were estimated using the robust estimators due to Dowd $(1984)^{54}$ and to Cressie and Hawkins $(1980)^{55}$. These alternative estimators were considered because, although a marginal outlier (an unusual datum as it appears on the overall distribution) was removed, spatial outlier(observations unusual in its spatial context) can inflate estimates of the semivariance ${ }^{26}$. An exponential variogram model ${ }^{24}$ was fitted by weighted least squares, and then tested by cross-validation. In cross-validation each observation was, in turn, removed and predicted from the remaining observations by ordinary kriging. The squared cross-validation error at each site was standardized by dividing by the ordinary kriging variance. The median standardized squared prediction error (SSPE) has an expected value of 0.455 in the case of a valid underlying variogram model with kriging errors that appear normally distributed ${ }^{25}$. The estimator due to Matheron $(1962)^{23}$ is more statistically efficient than the robust alternatives, so if the model fitted to these estimates appeared correct from the cross-validation results (median SSPE) then the alternatives were not considered. If the SSPE suggests that the model fitted to Matheron estimates are affected by outliers, then the models fitted to robust estimates are also cross-validated, and one is selected on the cross-validation results. This procedure follows the recommendations of Lark $(2000)^{26}$.

Our spatial analysis is focused on WRA because this was the demographic group with the largest sample size with coverage of 315 out of 343 enumeration areas. The statistical summary for WRA is shown in Supplementary Figure S3.

Ethical approval. This study was conducted according to the national research ethics guideline by the Ethiopian Science and Technology Ministry. All procedures involving human subjects were approved by the National Health Research Ethics Review Committee at the Ethiopian Science and Technology Ministry (Reference 3.10/433/06) and support letters were obtained from the respective regional and local health bureaus. Adult participants gave informed consent for their participation. Informed consent was also obtained from mothers or guardians for their children to participate in the study. In addition, assent was obtained from participating school age children. A separate ethical approval was obtained for the present study from the Research Ethical Review Committee of the Ethiopian Public Health Institute (Protocol EPHI-IRB-140-2018). Archived serum samples were transferred from storage at EPHI to the University of Nottingham, UK for analysis under a Material Transfer Agreement.

\section{Data availability}

The data generated in this study is available based on acceptable reasoning from the corresponding authors.

Received: 10 November 2020; Accepted: 5 March 2021

Published online: 22 March 2021

\section{References}

1. Tsunehiro, O. et al. Efficiency of serum copper/zinc Ratio for differential diagnosis of patients with and without lung cancer. Biol. Trace Elem. Res. 42, 115-127 (1994).

2. Maret, W. The function of zinc metallothionein: A link between cellular zinc and redox state. J. Nutr. 130, 1455S-1458S (2000).

3. Dell, B. L. O. Role of zinc in plasma membrane function. J. Nutr. 130, 1432S-1436S (2000).

4. Bailey, R. L., West, K. P. Jr. \& Black, R. E. The epidemiology of global micronutrient deficiencies. Ann. Nutr. Metab. 66, 22-33 (2015).

5. Kumssa, D. B. et al. Dietary calcium and zinc deficiency risks are decreasing but remain prevalent. Sci. Rep. 5, 10974-10984 (2015).

6. Wessells, K. R. \& Brown, K. H. Estimating the global prevalence of zinc deficiency: Results based on zinc availability in national food supplies and the prevalence of stunting. PLoS ONE 7, 1-11 (2012).

7. Raiten, D. J., Ashour, F. A. S., Ross, A. C., Meydani, S. N. \& Dawson, H. D. Inflammation and nutritional science for programs / policies and interpretation of research evidence (INSPIRE). J. Nutr. 145, 1039S-1108S (2015).

8. Sandstead, H. H. Causes of iron and zinc deficiencies and their effects on brain. J. Nutr. 130, 347S-349S (2000)

9. Saloojee, H. \& Pettifor, J. M. Iron deficiency and impaired child development. BMJ 323, 1377-1378 (2001).

10. King, J. C. et al. Biomarkers of nutrition for development (BOND)-zinc review. J. Nutr. 146(Suppl), 858S-S885 (2016).

11. Joy, E. J. M. et al. Dietary mineral supplies in Africa. Physiol. Plant. 151, 208-229 (2014).

12. Berhe, K., Gebrearegay, F. \& Gebremariam, H. Prevalence and associated factors of zinc deficiency among pregnant women and children in Ethiopia : a systematic review and meta-analysis. BMC Public Health 19, 1-11 (2019).

13. Ayana, G. et al. Dietary zinc intake and its determinants among Ethiopian children 6-35 months of age. BMC Nutr. 4, 1-6 (2018).

14. UNICEF, World Bank, World Food Program, USAID ENGIN. Ethiopian National Micronutrient Survey Report (Addis Ababa, Ethiopia, 2016).

15. Belay, A. et al. Selenium deficiency is widespread and spatially dependent in Ethiopia. Nutrients 12, 1565 (2020).

16. Thurnham, D. I., Mccabe, Northrop-Clewes, G. P. A. \& Nestel, P. Effects of subclinical infection on plasma retinol concentrations and assessment of prevalence of vitamin A deficiency: Meta-analysis. Lancet 362, 2052-2058 (2003).

17. Brown, K. H. Effect of infections on plasma zinc concentration and implications for zinc status assessment in low-income countries. Am. J. Clin. Nutr. 68, 425S-S429 (1998).

18. Brown, K. H. et al. Potential magnitude of the misclassification of a population's trace element status due to infection: Example from a survey of young Peruvian children. Am. J. Clin. Nutr. 58, 549-554 (1993). 
19. Likoswe, B. H. et al. Inflammation adjustment by two methods decreases the estimated prevalence of zinc deficiency in malawi. Nutrients 12, $1563(2020)$.

20. Mcdonald, C. M. et al. Adjusting plasma or serum zinc concentrations for inflammation : biomarkers reflecting inflammation and nutritional determinants of anemia (BRINDA) project. Am. J. Clin. Nutr. 927-937 (2020).

21. Thurnham, D. I. et al. Adjusting plasma ferritin concentrations to remove the effects of subclinical inflammation in the assessment of iron deficiency: A meta-analysis. Am. J. Clin. Nutr. 92, 546-555 (2010).

22. Namaste, S. M. L., Aaron, G. J., Varadhan, R., Peerson, J. M. \& Suchdev, P. S. Methodologic approach for the biomarkers reflecting inflammation and nutritional determinants of anemia (BRINDA) project. Am. J. Clin. Nutr. 106, 333S-347S (2017)

23. Matheron, G. Traité de Géostatistique Appliqué, Tome 1. Memoires due Bureau de Recherches Géologiques et Minières; (Technip: Paris, France, 1962).

24. Oliver, M. A. \& Webster, R. Basic Steps in Geostatistics: The Variogram and Kriging (Springer, 2015).

25. Tukey, J. W. Exploratory Data Analysis; Addison- Wesley (Reading, 1977).

26. Lark, R. M. A comparison of some robust estimators of the variogram for use in soil survey. Eur. J. Soil Sci. 51, 137-157 (2000).

27. Mastrandrea, M. D. et al. Guidance Note for Lead Authors of the IPCC Fifth Assessment Report on Consistent Treatment of Uncertainties; Intergovernmental Panel on Climate Change (IPCC) (Switzerland, 2010).

28. Phiri, F. P. et al. The risk of selenium deficiency in Malawi is large and varies over multiple spatial scales. Sci. Rep. 9, 6566 (2019).

29. Lark, R. M. et al. Mapping trace element deficiency by cokriging from regional geochemical soil data: A case study on cobalt for grazing sheep in Ireland. Geoderma 226, 64-78 (2014).

30. Hennigar, S. R., Lieberman, H. R., Fulgoni, V. L. \& McClung, J. P. Serum zinc concentrations in the US population are related to sex, age, and time of blood draw but not dietary or supplemental zinc. J. Nutr. 148, 1341-1351 (2018).

31. Arnaud, J. et al. Determinants of serum zinc concentrations in a population of French middle-age subjects (SU.VI.MAX cohort). Eur. J. Clin. Nutr. 64, 1057-1064 (2010).

32. Brown, K.H. et al. International zinc nutrition consultative group (IZiNCG) technical document \#1. Assessment of the risk of zinc deficiency in population and options for its control. Food Nutr. Bull. 25, S99-S203 (2004).

33. Hotz, C., Peerson, J. M. \& Brown, K. H. Suggested lower cutoffs of serum zinc concentrations for assessing zinc status : reanalysis of the second national health and nutrition examination survey data (1976-1980). Am. J. Clin. Nutr. 78, 756-764 (2003).

34. Tessema, M. et al. Soil zinc is associated with serum zinc but not with linear growth of children in Ethiopia. Nutrients 11, 221 (2019).

35. Belay, A., Marquis, G. \& Desse, G. Effect of socio-demographic factors on zinc status of infants and preschool children in east Gojjam, Amhara Region of Ethiopia. J. Food Sci. Eng. 5, 22-36 (2015).

36. Amare, B. et al. Micronutrient levels and nutritional status of school children living in Northwest Ethiopia. Nutr. J. 11, 1-8 (2012).

37. Kumera, G. et al. Prevalence of zinc deficiency and its association with dietary, serum albumin and intestinal parasitic infection among pregnant women attending antenatal care at the University of Gondar Hospital, Gondar Northwest Ethiopia. BMC Nutr. $1,31(2015)$

38. Gebremedhin, S., Enquselassie, F. \& Umeta, M. Prevalence of prenatal zinc deficiency and its association with socio-demographic, dietary and health care related factors in Rural Sidama, Southern Ethiopia: A cross-sectional study. BMC Public Health 11, 898 (2011).

39. Hafebo, A. S. et al. Overview of the Ethiopian national food consumption survey (NFCS): implications for fortification programs overview of the ethiopian national food consumption survey ( NFCS ): implications for fortification programs. Eur. J. Nutr. Food Saf. 5, 961-962 (2015).

40. Central Statistical Agency of Ethiopia. Household consumption and expenditure survey 2010/11: Analytical report (Statistical Bulletin 563 (Central Statistical Agency of Ethiopia, 2012).

41. Manzeke, M. G. et al. Fertilizer management and soil type influence grain zinc and iron concentration under contrasting smallholder cropping systems in Zimbabwe. Sci. Rep. 9, 1-13 (2019).

42. Benoist, B. D., Darnton-hill, I., Davidsson, L., Fontaine, O. \& Hotz, C. Conclusions of the Joint WHO/UNICEF/IAEA/IZiNCG Interagency meeting on zinc status indicators. Food Nutr. Bull. 28, 480S-484S (2007).

43. Mao, H. et al. Using agronomic biofortification to boost zinc, selenium, and iodine concentrations of food crops grown on the loess plateau in China. J. Soil Sci. Plant Nutr. 14, 459-470 (2014).

44. Liu, D., Liu, Y., Zhang, W., Chen, X. \& Zou, C. Agronomic approach of zinc biofortification can increase zinc bioavailability in wheat flour and thereby reduce zinc deficiency in humans. Nutrients 9,465 (2017).

45. Zia, M. H. et al. Site-specific factors influence the field performance of a zn-biofortified wheat variety. Front. Sustain. Food Syst. 4, 135 (2020).

46. Fujii, T., Shonchoy, A. S. \& Xu, S. Impact of electrification on children's nutritional status in rural Bangladesh. World Dev. 102, 315-330 (2018).

47. Majid, H. Increased rural connectivity and its effects on health outcomes. Lahore J. Econ. 18, 271-282 (2013).

48. Gashu, D. et al. Spatial prediction of the concentration of selenium (Se) in grain across part of Amhara Region Ethiopia. Sci. Total Environ. 733, 139231 (2020).

49. Population Census Commission. Summary and Statistical Report of the 2007 Population and Housing Census. Population Size by Age and Sex Population Census Commission: (Addis Ababa, Ethiopia, 2008).

50. WHO. WHO guidelines on drawing blood: best practices in phlebotomy (WHO: Geneva, Switzerland, 2010).

51. Gashu, D., Marquis, G. S., Bougma, K. \& Stoecker, B. J. Spatial variation of human selenium in Ethiopia. Biol. Trace Elem. Res. 189, 354-360 (2019).

52. Hijmans, R.J. Geosphere: Spherical Trigonometry (R package version 1.5-7. 2017). Available https://CRAN.R-project.org/package= geosphere.

53. Gneiting, T. Strictly and non-strictly positive definite functions on spheres. Bernoulli 19, 1327-1349 (2013).

54. Dowd, P.A. The variogram and kriging: Robust and resistant estimators In Geostatistics for Natural Resources Characterization (Verly, G., David, M., Journel, A.G., Marechal, A., Eds.; Reidel: Dordrecht, pp. 91-106; The Netherlands, 1984).

55. Cressie, N. \& Hawkins, D. Robust estimation of the variogram. Math. Geol. 12, 115-125 (1980).

\section{Author contributions}

A.B., D.G., E.J.M.J., R.M.L. and M.R.B. designed the research; A.B. and D.Z. supervised data collection; A.B., S.D.Y., E.H.B. conducted the laboratory analysis; A.B., E.L.A., and R.M.L. performed statistical analysis; R.M.L. and C.C. prepared Figs. 1, 2, 3, 4 and 5; BHL adjusted serum zinc data for inflammation. All authors reviewed the manuscript.

\section{Funding}

This research was funded by the Bill \& Melinda Gates Foundation (BMGF) through the GeoNutrition project (INV-009129). The funder had no role in the design, execution, analyses or interpretation of the data. 


\section{Competing interests}

The authors declare no competing interests.

\section{Additional information}

Supplementary Information The online version contains supplementary material available at https://doi.org/ 10.1038/s41598-021-85977-x.

Correspondence and requests for materials should be addressed to D.G.

Reprints and permissions information is available at www.nature.com/reprints.

Publisher's note Springer Nature remains neutral with regard to jurisdictional claims in published maps and institutional affiliations.

(c) (1) Open Access This article is licensed under a Creative Commons Attribution 4.0 International License, which permits use, sharing, adaptation, distribution and reproduction in any medium or format, as long as you give appropriate credit to the original author(s) and the source, provide a link to the Creative Commons licence, and indicate if changes were made. The images or other third party material in this article are included in the article's Creative Commons licence, unless indicated otherwise in a credit line to the material. If material is not included in the article's Creative Commons licence and your intended use is not permitted by statutory regulation or exceeds the permitted use, you will need to obtain permission directly from the copyright holder. To view a copy of this licence, visit http://creativecommons.org/licenses/by/4.0/.

(C) The Author(s) 2021 